\title{
A Review on the Application of Ionic Liquids for the Radioactive Waste Processing
}

\section{방사성 폐기물 처리를 위한 이온성 액체 활용}

Byung Heung Park

Korea National University of Transportation, 50 Deahak-ro, Chungju-si, Chungbuk, Korea

박병흥

한국교통대학교, 충청북도 충주시 대학로 50

(Received September 17, 2013 / Revised November 20, 2013 / Approved December 3, 2013)

Academic interests in ionic liquid (IL) technologies have been extended to the nuclear industry and the applicability of ionic liquids for processing radioactive materials have been investigated by many researchers. A number of studies have reported interesting results with respect to the spectroscopic and electrochemical behaviors of metal elements included in spent nuclear fuels. The measured and observed properties of metal ions in TBP(tri-butyl phosphate) dissolved ILs have led the development of alternative technologies to traditional aqueous processes. On the other hand, the electrochemical deposition of metal ions in ILs have been investigated for the application of the solvents to aqueous as well as to non-aqueous processes. In this work, a review on the application of ILs in nuclear fuel cycle is presented for the purpose of categorizing and summarizing the notable researches on ILs.

Keywords: Ionic liquids, Spent nuclear fuel, Extraction, Electrochemical deposition, Radiochemical stability

이온성 액체 기술에서의 학문적 연구들은 원자력 산업으로 확대되어 왔으며 많은 연구자들에 의해 방사성 물질의 처리에 이 온성 액체의 활용이 연구되어 왔다. 다수의 연구들에 의해 사용후핵연료에 포함되어 있는 금속 원소들의 분광학적, 전기화 학적 거동에 대한 흥미로운 결과들이 보고되었다. TBP(tri-butyl phosphate)를 용해시킨 이온성 액체에서 측정되고 관찰된 금속 이온들의 물성들은 전통적인 수용성 공정에 대한 대안 기술 개발을 유발시켰다. 한편, 수용성 및 비수용성 공정에서의 활용을 위해 이온성 액체에서 금속 이온의 전기화학적 전착이 연구되었다. 본 연구에서는 이온성 액체 연구에서 주목할 만 한 내용들을 분류하고 정리하여 핵연료주기에서 이온성 액체의 활용에 대해 고찰하였다.

중심단어: 이온성 액체, 사용후핵연료, 추출, 전해전착, 방사화학 안정성

${ }^{*}$ Corresponding Author.

Byung Heung Park, Korea National University of Transportation, E-mail: b.h.park@ut.ac.kr, Tel: +82-43-841-5226 


\section{1. 서 론}

원자력에 의한 전력 생산은 화석 연료를 이용한 방법들 과는 달리 온실가스를 발생시키지 않는 방법이다. 현재 인 류가 소비하는 에너지를 섹터별로 나눈다면 교통, 산업, 주 거/상업과 전력으로 구분할 수 있다. 미국의 경우 2011년을 기준으로 이들은 각각 $28 \%, 21 \%, 11 \%, 40 \%$ 를 차지하고 있 으며 원자력에서 생산되는 에너지는 모두 전력으로 사용되 고 석유는 대부분(93\%)이 교통을 위한 에너지원으로 사용 된다[1]. 최근에는 교통에서 발생되는 온실가스 저감을 위하 여 전기차량과 같은 전기적 에너지를 이용하는 교통 수단이 활발히 개발되고 있으며 이는 에너지 섹터 구분에서 교통과 전력의 결합을 가속화시키는 결과를 초래하게 된다. 교통과 전력이 결합되는 동시에 온실가스를 저감시킬 수 있는 방법 은 전력 생산에서 발생되는 온실가스를 최소화시키는 것으 로 이는 원자력 에너지의 활용이 현재 보다 증가할 수 있음 을 의미한다.

원자력 발전에서는 특성상 방사성 폐기물들이 발생되며 원자력 에너지의 확대는 전력 생산 후 발생되는 사용후핵연 료를 포함한 이러한 방사성 폐기물 관리 기술 수준에 의존하 게 될 것이다. 사용후핵연료 재처리는 20 세기 중반부터 연구 되었으며 현재 일부 국가에서는 상업적으로 재처리를 수행 하고, 일부 국가에서는 직접처분을 결정하였으며, 재처리를 수행하는 국가들을 포함한 여러 국가들에서는 재처리에서 발생되는 폐기물 감소와 사용후핵연료 내 유용한 자원들의 재활용을 위해 다양한 공정들을 개발하고 있다[2,3].
현재 상업적으로 활용되고 있는 유일한 공정은 PUREX 이며 이는 대표적인 습식공정으로 액-액 추출원리에 기초 하고 있다. PUREX 공정은 시행하는 국가들에서 각각 다 소 변형된 형태로 적용되나 일반적으로는 Fig. 1 과 같은 1 차 정제 사이클로부터 시작한다. PUREX 공정에서는 1 차적 으로 사용후핵연료는 질산 용액에 용해된다. 우라늄과 플 루토늄은 사용후핵연료를 용해시킨 질산 용액으로부터 ndodecane(n-DD) 또는 등유(kerosene)와 같은 불활성 지방 족 희석제에 의해 용해된 30\%(v/v) (약 $1.1 \mathrm{M}$ ) 농도의 tributyl phosphate(TBP) 유기상으로 $\mathrm{Pu}^{+4}$ 와 $\mathrm{UO}_{2}^{+2}$ 형태로 추 출된다[4]. 첫 추출 공정에서 대부분의 분열생성물들은 수용 액상에 잔류하게 되고 유기상의 $\mathrm{Pu}^{+4}$ 는 $\mathrm{NH}_{2} \mathrm{OH}$ 에 의해 $\mathrm{Pu}^{+3}$ 로 환원되어 $6 \mathrm{M}$ 질산 수용액으로 역추출 된다. 유기상에 잔 존하게 된 우라늄은 희석 질산에 의해 역추출 되어 회수된다.

PUREX와 같은 습식공정의 대안으로 건식공정들이 1990 년대부터 본격적으로 개발되기 시작하였다. 대표적인 공정은 파이로 공정으로 불리는 고온 용융염 전해 공정이 다. 파이로 공정은 초기에는 금속핵연료 처리를 위해 개발 되었으며[5] 환원 공정의 도입[6,7]으로 산화물 사용후핵연 료로 적용이 확대되었다. 한국에서는 한국원자력연구원 (KAERI, Korea Atomic Energy Research Institute) 주도로 미국 ANL(Argonne National Laboratory)에서 제안된 파이로 공정을 골격으로 전해환원, 폐용융염 처리 공정을 추가하여 전체적인 파이로 공정 흐름을 완성하였으며 각 공정별로 활 발하게 기술을 개발하고 있다[8,9]. 파이로 공정은 전기화학 적 방법으로 환원된 사용후핵연료 금속 환원체를 $\mathrm{LiCl}-\mathrm{KCl}$ 공

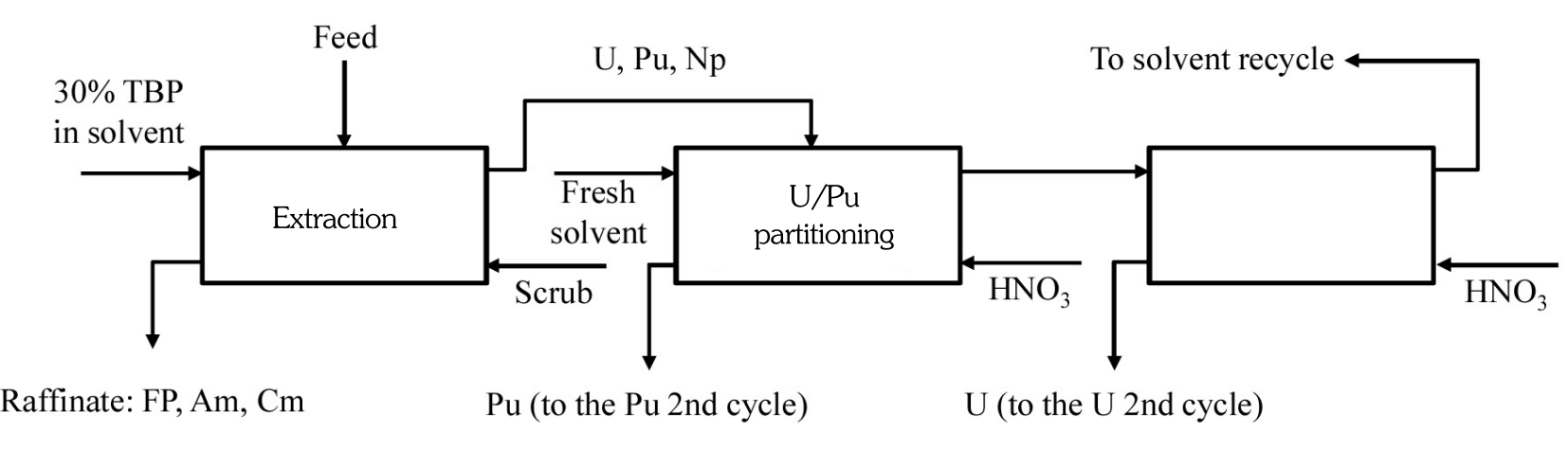

Fig. 1. First purification cycle in PUREX process. 
융염 매질에서 전해-전착 과정으로 회수하는 방법으로 U을 제외한 악티나이드들을 액체 음극에 함께 전착시켜 PUREX 공정과 달리 순수한 $\mathrm{Pu}$ 을 얻지 않도록 구성되었다.

최근에는 사용후핵연료 처리 공정에 화학 공정에서 유기 용매를 대체할 수 있는 친환경 매질로 사용되는 이온성 액체 의 적용이 시도되고 있다[10-12]. 이러한 기술들은 그 적용 가 능성에 비해 국내 연구가 미진한 분야이며 여러 다른 국가들 의 기술에 뒤처지지 않기 위해서는 시급히 기술 개발이 시도 되어야하는 분야이기도 하다. 본 연구에서는 연구자들이 이 온성 액체를 활용한 후행핵연료 주기 공정 개발 단계로 진입 을 원활하게하기 위해 기존 연구들의 접근 방법들과 주요 결 과들을 정리하였으며 현황과 주요 이슈들을 검토하였다. 이 를 위해 이온성 액체 연구자들에 초점을 둔 검토 논문들[1012]의 범위를 벗어나 사용후핵연료 공정에 관심 있는 연구자 들을 위해 이온성 액체의 설명을 강화하였으며 앞선 검토 논 문들이 담지 못한 최근 연구들을 포함하였다.

\section{2. 이온성 액체}

이온성 액체(IL, Ionic Liquid)는 일반적으로 상온에서 액 체 상태를 나타내는 유기염을 일컫는 용어로 사용된다[13]. 대부분 이온성 액체의 용융점은 $100^{\circ} \mathrm{C}$ 이하로 이들 중 특히 실온에서 액체로 존재하는 물질들은 실온 이온성 액체(RTIL, Room Temperature Ionic Liquid)로 불리고 있다. 순수한 물 질의 액체 상태가 이온들로 구성되었다는 측면에서 파이로 공정에서 사용되는 용융염과 개념적으로는 동일하여 이온성 액체를 용융염의 일종으로 분류할 수도 있으나 무기염들인 용융염과 달리 낮은 온도에서 액체 상태를 나타내는 특징으 로 인해 일반적으로는 용융염과 분리하여 정의한다[14]. 이 렇게 낮은 용융점을 갖는 특징이 나타나는 이유는 음이온과 양이온의 크기 차이로 설명된다. 보편적으로 사용되는 이온 성 액체들의 양이온들은 Fig. 2(a)와 같이 크기에서 음이온 들(Fig. 2(b))과 큰 차이를 보이고 있으며 이로 인해 이온들 의 결합에 입체장애(steric hindrance)가 발생하기 때문에 상 온에서도 양이온-음이온 사이에 강한 결합이 발생하지 않고 액체 상태를 유지하는 것으로 알려져 있다.

이온성 액체는 양이온의 이름이 복잡하기 때문에 보통 축약형으로 표시된다. Fig. 2(a)에서 보인 것과 같이 양이온 의 고리 형태에 알킬기가 다양한 위치에 존재할 수 있으며 특 정 위치를 차지한 알킬기의 이름을 붙여, 예를 들면, imidaz-

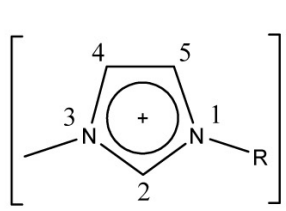

1-alkyl-3-methylimidazolium<smiles>[R][N+]([R])([R])[B]C</smiles>

Tetraalkylammonium

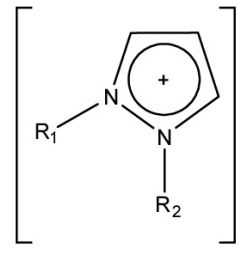

1,2-dialkylpyrazolium

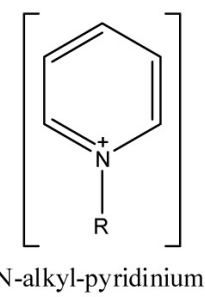

$\mathrm{N}$-alkyl-pyridinium

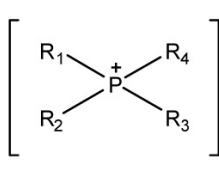

Tetraalkylphosphonium

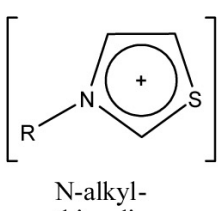

thiazolium

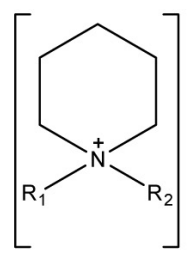

N-alkylN-methylpiperidinium

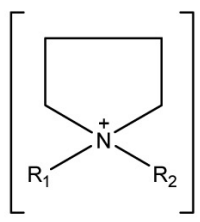

$\mathrm{N}$-alkylN-methylpyrrolidinium

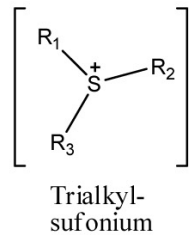

(a) Cations; $R=$ alkyl group

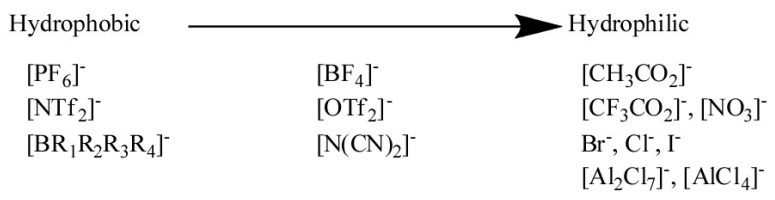

(b) Anions

Fig. 2. Some cations and anions for ILs.

olium기의 1,3 위치에 각각 butyl기와 methyl기가 존재하는 1-butyl-3-methylimidazolium은 축약하여 [bmim]로 표현되 고 1,3 위치에 octyl기와 methyl기가 각각 존재하는 1-octyl3-methylimidazolium은 [omim]으로 표시된다. 최종적으로 이와 결합한 Fig. 2(b)와 같은 음이온의 종류를 함께 표시하 여, 예를 들면 앞에서 언급된 [bmim] 양이온에 $\mathrm{Cl}$ 가 결합된 경우는 $[\mathrm{bmim}][\mathrm{Cl}]$ 과 같이 이온성 액체가 표현된다. 이온성 액체는 여러 무기물, 유기물, 고분자 물질을 용해시킬 수 있 고, 다양한 양이온과 음이온을 조합하여 소수성, 용해도, 점 도, 밀도 등의 물리화학적 특성을 쉽게 변화시킬 수 있어서 
“Designer Solvent”로도 불리고 있으며 이론상으로 양이온 과 음이온의 조합으로 $10^{18}$ 가지 이상의 합성이 가능하여 유 기 용매의 대체 용매로서 커다란 잠재력을 지니고 있다[15].

이온성 액체가 지닌, 일반적인 유기 용매와 대비되는 대 표적인 물성들은 비휘발성, 고전도성, 불연성 성질을 들 수 있으며 이를 활용하면 휘발성유기화합물(VOC)을 배출하지 않는 친환경 공정을 개발할 수 있다. 기존 유기 용매가 사용 되던 금속이온 추출에 적용되는 대체 용매로서 이온성 액 체의 활용은 1990년대 후반부터 주목 받기 시작했다[16-19].

추출 공정에 활용되기 위해서는 수용액에 존재하는 금속 이온을 추출한 후 액-액 상분리를 유발시켜야하므로 이온성 액체는 소수성을 지녀야 한다. 이러한 소수성 환경은 이온성 액체에 의해 만들어지며 실제 금속 이온 추출은 추출제를 사 용하여 얻게 된다. 따라서 금속 이온의 특징에 따라 다양한 추출제가 소수성 성질을 지닌 1-alkyl-3-methylimidazolium hexafluorophosphate $\left(\left[\mathrm{C}_{\mathrm{n}} \mathrm{mim}\right]\left[\mathrm{PF}_{6}\right]\right)$ 희석제에서 시도되어 분배율 향상을 보였으며[17] 이를 활용하여 목적에 맞도록 이온성 액체의 종류를 변화시킬 수 있었다[18]. 그러나, 일부 연구에서는 이온성 액체의 활용성은 용해 손실과 추출된 금 속 이온들의 회수에서의 어려움에 의해 제한될 수 있음이 지 적되었다[19].

금속 추출제의 희석제로서의 역할과 함께 이온성 액체에 서 주목해야할 물성은 전기화학적 성질로, 이온성 액체는 넓 은 전기화학 창(electrochemical window)을 지니고 있어 전 기화학 반응에서 안정적인 전해질로 사용될 수 있다[20]. 다 양한 양이온-음이온 조합에 의해 전기화학 창의 범위가 의존 하며 일반적으로 이온성 액체는 3 에서 $6 \mathrm{~V}$ 까지 넓은 전위창 을 보이고 있다[21]. 또한, 전극을 금, 백금, 탄탈륨, 글래시 카본 등으로 다양하게 변화시키면 전기화학 창을 $1 \mathrm{~V}$ 정도 는 변화시킬 수 있음이 밝혀졌으며[22] 용액의 산도(acidity) 를 조절함으로서도 전기화학 창을 변화시킬 수 있는 것으로 나타났다[23]. 이온성 액체 매질에서 전기화학적 방법으로 금 속 이온을 전착시킬 수 있기 때문에 수용성(aqueous) 공정에 서 추출 기술을 적용하였을 경우에는 추출 후 금속 이온을 전 기화학적으로 회수할 수 있으며 비수용성(non-aqueous) 공 정에서는 직접 금속 이온을 전착시킬 수 있게 되었다[24,25].

\section{3. 사용후핵연료 처리를 위한 이온성 액체 활용}

전통적으로 사용후핵연료 처리를 위한 공정들은 습식과
건식으로 구분되어 설명되어왔다. 추출 방법을 사용하여 수 용액을 처리하는 공정을 습식으로, 처리 공정에 수용액이 사 용되지 않는 공정들을 건식으로 지칭하는 것이 일반화되었 으나 이온성 액체를 이용한 공정들을 이러한 기준으로 나누 는 것은 다소 모호한 측면이 있다. 따라서, 본 논문에서는 습 식/건식 공정의 표현을 피하고 보다 명확한 의미가 전달 될 수 있도록 수용성(aqueous)/비수용성(non-aqueous) 공정 으로 구분하여 정리하였다.

사용후핵연료 처리 공정에서 활용되는 이온성 액체의 대 표적인 물성은 안정적인 추출 희석제로서의 역할과 전기화 학적 매질로서의 역할이다. 이 중 수용성 공정에서는 추출 희 석제로 사용된 후 전기화학 매질로 사용되어 추출된 금속 원 소들의 최종 회수에 이 두 가지 성질들이 모두 활용되는 것 으로 생각할 수 있다. 반면, 이 두 성질 중 전기화학 매질로서 의 성질만을 이용하는 공정을 본 논문에서는 비수용성 공정 으로 분류하였다. 따라서 금속 원소들의 전기화학적 석출 거 동을 연구한 논문들 중에서 추출제가 포함된 시스템을 대상 으로 하는 경우는 수용성 공정으로, 추출제에 대한 언급 없이 전기화학적 거동을 중심으로 연구된 논문들은 비수용성 공 정으로 분류하였다. 수용성 공정에는 기존 PUREX 공정에서 사용되던 n-DD나 등유의 대체를 위해 이온성 액체를 사용한 기술들로, 수용액 상에서 금속 원소들을 추출시킨 후 이온성 액체 상에서 전기화학 방법으로 금속을 회수하는 공정을 포 함시켰다. 비수용성 공정은 이온성 액체 상에 금속이온을 용 해시켜 전기화학적으로 회수하는 공정으로, 추출제와 수용 액이 관련되지 않는 공정을 대상으로 하였다.

\section{1 수용성 공정에서의 이온성 액체 활용}

이온성 액체를 사용하여 우라늄을 포함하는 f-궤도 원소 들을 추출하기 위한 연구는 2000년대 초반부터 진행되었다 [26,27]. Visser와 Rogers는[26] 1-alkyl-3-butylimidazolium 양이온에 두 종류의 음이온을 결합시키는 한편 알킬기의 길 이를 변화시켜 수용액 상으로부터 악티나이드를 추출하여 이온성 액체의 추출 공정 적용 가능성을 제시하였다. 이러한 연구들을 바탕으로 최근 Kolarik[27]은 f-궤도 원소 추출의 희 석제로서 이온성 액체의 주요 물성들인 용점, 밀도, 물과의 상호 용해도, 점도 등을 정리하였으며 분자 희석제와 비교하 여 효율과 메카니즘을 설명하였다.

PUREX 공정에 사용되는 유기용매(n-DD 또는 등유)를 대체하여 $\mathrm{TBP}$ 를 용해시키기 위한 희석제로서의 이온성 액 
체의 적용 가능여부는 우라늄 추출을 중심으로 연구되었다 [28-31]. 질산에 용해된 우라늄 추출을 위해 $1.1 \mathrm{M} \mathrm{TBP}$ 를 $[\mathrm{bmim}]\left[\mathrm{PF}_{6}\right]$ 이온성 액체에 희석시켜 두 용액을 접촉시킨 결 과 우라늄의 분배율은 질산 농도 0.01 에서 $4 \mathrm{M}$ 범위에서는 $1.1 \mathrm{M} \mathrm{TBP} / \mathrm{n}-\mathrm{DD}$ 시스템과 유사한 수치로 나타났으며 질 산 농도가 $4 \mathrm{M}$ 을 넘어서는 범위에서도 분배율이 증가하여 $\mathrm{n}-\mathrm{DD}$ 를 사용한 경우보다 우수한 것으로 결과가 발표되었다 [28]. 동일한 연구에서 추출제를 첨가하지 않고 이온성 액체 만을 접촉시켰을 때에는 단지 소량의 우라늄만이 추출되는 결과도 함께 제시되었다[28]. 1-alkyl-3-methylimidazolium 의 알킬기를 변경하여 가지가 좀 더 긴 octyl기를 연결한 $[\mathrm{omim}]\left[\mathrm{PF}_{6}\right]$ 를 희석제로 사용한 비교 연구에서는 $1.1 \mathrm{M} \mathrm{TBP} /$ [omim] $\left[\mathrm{PF}_{6}\right]$ 에서 우라늄의 분배율이 모든 질산 농도 범위에 서 [bmim] $\left[\mathrm{PF}_{6}\right]$ 보다 다소 낮았으나 [omim][ $\left.\mathrm{PF}_{6}\right]$ 의 질산에 대 한 용해도는 $[\mathrm{bmim}]\left[\mathrm{PF}_{6}\right]$ 에 비해 두세 배 낮은 것으로 관찰 되었다[29]. 후속 연구로 $1.1 \mathrm{M} \mathrm{TBP} /[\mathrm{bmim}]\left[\mathrm{NTf}_{2}\right]$ 를 사용하 여 질산에 용해된 우라늄을 추출하여 분배율이 $1.1 \mathrm{M} \mathrm{TBP/}$ $[\mathrm{bmim}]\left[\mathrm{PF}_{6}\right]$ 와 $1.1 \mathrm{M} \mathrm{TBP} / \mathrm{n}-\mathrm{DD}$ 시스템의 결과와 비교되었 으며 더 나아가 추출된 우라늄을 포함하고 있는 이온성 액체 상으로부터 전기화학적 방법으로 우라늄 산화물을 전착시켰 다[30]. 우라늄 이온을 전착시키는 연구는 PUREX 공정에 이 온성 액체를 적용시키기 위해서는 필수적으로 연구되어야하 는 분야이며 최근에는 우라늄 이온의 이온성 액체에서의 전 기화학적 물성이 측정되어 $[\mathrm{bmim}][\mathrm{Cl}]$ 계에서 $\mathrm{U}(\mathrm{VI})$ 의 확산 계수와 활성화 에너지가 보고되기도 했다[31]. 유기상인 이 온성 액체에서 금속을 전기화학적으로 얻게 되면 다량의 액 체 폐기물을 발생시키는 탈거공정(stripping)이 필요 없게 되 므로 공정 효율이 크게 향상될 것이 예상된다. 한편, 상업규 모 액-액 추출에 사용되기 위해 필요한 밀도, 용해도, 점도 등 의 물성을 TBP를 용해시킨 1-alkyl-3-methlyimidazolium 계 를 대상으로 검토한 결과 실제 재처리 공정에서 적용에는 한 계가 있을 수 있다는 것이 지적되기도 하였다[32].

수용성 공정에 대해서는 이와 같이 TBP를 사용한 분배율 측정 연구가 가장 활발히 진행되고 있으며 우라늄 추출의 경 우 이러한 시스템의 메카니즘 규명과 새로운 이온성 액체의 활용 또한 모색되고 있다. 이온성 액체는 분자 희석제인 유기 용매와는 달리 양이온과 음이온이 존재하므로 추출된 우라 늄 이온의 배위 환경(coordination environment)이 기존 용 매계와는 전혀 다른 형태로 나타나게 된다. 이를 밝히기 위해 분광학적 방법이 사용되었으며[33,34] 이와 함께 TBP를 사 용한 추출 메카니즘이 연구되어 수용액의 nitrate 농도가 증
가함에 따라 이온 교환 과정에서 중성의 uranyl-TBP-nitrato 복합물의 추출로 전환되는 것으로 제시되었다[35]. 1-alkyl3-methylimidazolium 계는 이온성 액체들 중에서 가장 많이 알려진 물질들이다. 그러나, 앞서 언급한 것과 같이 이온성 액체의 가장 큰 장점은 목적에 맞도록 이온성 액체를 구성할 수 있다는 것이다. 이러한 시도로 우라늄 추출을 위해 새로 운 phosphoryl 그룹이 포함된 이온성 액체가 합성되어 적용 되기도 하였으며[36] 암모늄 계열의 이온성 액체가 합성되어 $\mathrm{TBP}$ 를 이용한 질산 수용액 내의 우라늄 추출에 사용되어 질 산 농도의 변화에 따른 추출 성능이 측정된 결과로 높은 질 산 농도 $(>0.1 \mathrm{M})$ 에서 소수성 이온성 액체 시스템의 추출율 이 증가하는 것이 관찰되었다[37]. 사용후핵연료 처리 공정 을 위해 개발된 것은 아니지만 환경 우라늄 추출을 위해 새 롭게 적용된 tricaprylmethylammonium thiosalicylate 역시 우라늄 추출을 위한 새로운 이온성 액체의 개발로서 언급될 수 있다[38].

우라늄을 제외한 악티나이드들의 추출 연구는 란타나이 드와 함께 존재하는 계를 대상으로 연구되고 있다. 이러한 연구들은 PUREX 공정을 염두해 둔 것은 아니며 따라서 TBP 를 추출제로 사용하지는 않고 있다. Pyridine 계열의 이온성 액체를 사용하여 $\mathrm{Eu}(\mathrm{III})$ 과 $\mathrm{Am}(\mathrm{III})$ 가 용해되어 있는 산 용액 ( $\leq 1 \mathrm{M} \mathrm{HNO}_{3}$ )으로부터 선택적으로 $\mathrm{Am}(\mathrm{III})$ 을 추출할 수 있 었으며 높은 분리율을 $(\leq 150)$ 얻을 수 있었다[39]. 최근에 는 추출제를 사용하지 않고 [omim][PF, $]$ 로 Ce(IV)을 Th(IV) 과 란타나이드(III)들의 혼합 용액에서 성공적으로 분리한 연 구가 발표되기도 했다[40]. 란타나이드 시스템에서는 추출을 위해서 이온성 액체에 TODGA를 추출제로 사용하여 $\mathrm{La}(\mathrm{III})$ $\mathrm{Eu}(\mathrm{III}), \mathrm{Lu}(\mathrm{III})$ 에 대해 희석제로 iso-octane을 사용한 경우 에 비해 우수한 결과를 얻은 연구[41]와 organophosphorous 추출제를 사용하여 imidazolium 계열 이온성 액체에서 란타 나이드를 추출한 연구[42]를 주목할 수 있을 것이다. Senguta 등[43]은 tripodal diglycolamide(T-DGA)를 imidazolium 계 열의 이온성 액체에 용해시킨 용액을 사용하여 Am(III)를 추 출하였으며 T-DGA의 배위 속도가 늦기 때문에 TODGA 시 스템과 비교하여 평형시간이 길어진다는 결과를 발표하였 다.

사용후핵연료에 존재하는 핵종 중에서 란타나이드와 함 께 주요 관심이 되는 분열생성물들은 Cs과 $\mathrm{Sr}$ 이다. 이들은 고 방열성 특성이 있기 때문에 폐기물에서 제거되어 별도로 관 리된다면 폐기물의 열 및 방사성 부하를 크게 낮출 수 있게 된다. 수용액 상에서부터 Cs과 $\mathrm{Sr}$ 의 추출은 crown ether 계 
열의 추출제를 사용하여 연구되어왔다[44-48]. 1990년대 후 반 crown ether를 추출제로 하였을 때 이온성 액체의 매질 로서의 사용가능성이 제시[44]된 이후에 crown ether 계열의 18-crown-6(18C6), dicyclohexano-18-crown-6(DCH18C6), 4,4'(5')-di-(tert-butylcyclohexano)-18-crown-6(Dtb18C6) 가 $\left[\mathrm{C}_{\mathrm{n}} \mathrm{mim}\right]\left[\mathrm{PF}_{4}\right]$ 이온성 액체에 용해되어 $\mathrm{Na}^{+}, \mathrm{Cs}^{+}, \mathrm{Sr}^{2+}$ 이온 의 추출에 사용되어 추출제 없이는 추출 성능이 나타나지 않 으며 추출 성능은 crown ether의 소수성에 의존함이 밝혀졌 다[45]. 또한, 높은 $\mathrm{HNO}_{3}$ 농도에서는 $\mathrm{PF}_{6}$ 가 분해되어 이온성 액체 내 포함된 물의 함량이 증가되는 것으로 나타났다[45]. DCH18C6를 사용하여 imidazolium 계열의 이온성 액체에서 $\mathrm{Sr}^{2+}$ 를 추출한 연구에서는 추출이 양이온 교환을 통해 진행 되며 crown ether에 복합체로 추출되는 것이 보고되었으며 [46] 알카리 염화물 용액에서는 이온성 액체의 알킬기의 크 기가 증가함에 따라 추출 효율이 저하되는 것으로 나타난 반 면 알카리 금속 이온의 추출 선택도와 효율은 수용액 상의 음 이온이 chloride, nitrate, sulfate 여부에 영향을 받지 않는 것 으로 분석되었다[47]. 최근에는 기능성 이온성 액체의 특성 을 살려 여러 분야에 적용되어 온 imidazolium 계열이 아닌 아마이드 계열의 이온성 액체가 합성되어 $\mathrm{Cs}^{+}$와 $\mathrm{Sr}^{2+}$ 추출에 적용되었다[48].

우라늄의 전기화학적 거동 연구에서와 동일하게, 추출된 $\mathrm{Cs}$ 과 $\mathrm{Sr}$ 이온들 역시 이온성 액체의 전기 전도성 특징을 활 용하면 전기화학적 방법으로 회수할 수 있다. Crown ether 계열의 추출제를 사용하여 수용액 상에서 이온성 액체 상으 로 추출된 $\mathrm{Cs}$ 과 $\mathrm{Sr}$ 의 전기화학적 거동이 수은을 작업전극으 로 하여 실험적으로 연구되었으며 추출제와 복합체를 형성 한 각 이온들의 환원 전위가 측정되었다. 수은 풀 (pool)을 전 극으로 사용하여 $90 \%$ 정도의 금속을 회수할 수 있음이 밝혀 졌으며[49] 수은 전극에서는 아멜감(amalgam)을 형성하는 것으로 나타났다[50].

\section{2 비수용성 공정에서의 이온성 액체 활용}

비수용성 공정에서는 악티나이드들과 분열생성물들로 구성된 사용후핵연료가 이온성 액체에 어떠한 형태로 용해 되는지 그 형태를 파악하는 것이 중요한 연구 주제이다. 사 용후핵연료를 대상으로 이러한 연구가 수행된 결과는 없으 며 개별 원소들에 대해 분광학적 연구를 통한 이온성 액체 종 류에 따른 배위 분석과 전기화학적 거동에 대한 연구들이 진 행되고 있다.
이온성 액체에 용해된 악티나이드 원소들의 배위에 대한 연구들은 최근 Cocaila 등[51]이 정리하여 보고하였다. COcaila 등은 imidazolium 계열에서 악티나이드 이온들의 분광 학과 전기화학 연구들을 요약함과 동시에 악티나이드 이온 들의 용매화(solvation) 결과를 밝히기 위한 컴퓨터 시뮬레 이션 결과를 언급하였다. 한편, 최근에는 $\mathrm{U}(\mathrm{VI})$ 에 중점을 두 고 이온성 액체에서 악티나이드 원소들의 복합체 형성, 전기 화학 거동, 추출 거동 등과 같은 악티나이드 화학에 대한 연 구들이 포럼 형태로 정리되기도 하였다[52].

이온성 액체에서 우라늄에 대한 전기화학적 거동에 관 한 연구는 이온성 액체가 주목 받기 시작한 초기부터 진행 되었다. 1980년대에는 $\mathrm{AlCl}_{3}$ 를 포함한 이온성 액체 용액에 서 산화수에 따른 우라늄 원소들의 이온 복합체와 환원 전 위 등이 연구되었다[53-55]. 이러한 연구들은 pyridinium 계 열의 이온성 액체를 사용한 것으로 산성 분위기[53]와 염기 성 분위기[54,55]의 이온성 액체에서 $\mathrm{U}(\mathrm{IV}) / \mathrm{U}(\mathrm{III})$ 의 환원전 위가 글래시 카본 전극에서 측정되었으며 전위차와 분광학 적 연구로 산성 분위기에서 우라늄 이온의 배위와 복합체가 연구되었다[55,56].

대표적 이온성 액체인 imidazolium 계열에서는 초기에 염화물 형태의 우라늄의 합성과, 구조 및 전기화학적 거동이 연구되었다[57]. 이 후 [bmim]에서 우라늄 염화물 복합체에 대한 전압곡선을 통해 $\mathrm{UCl}_{6}{ }^{-} / \mathrm{UCl}_{6}^{2-}$ 및 $\mathrm{UCl}_{6}{ }^{2-} / \mathrm{UCl}_{6}{ }^{3-}$ 의 환원 거 동을 확인하였으며 $\mathrm{U}(\mathrm{III})$ 에서 $\mathrm{U}(0)$ 로 환원되는 거동의 원인 으로 판단되는 비가역 양극 과정을 tri-n-butylmethylammonium 계열의 이온성 액체에서 측정하였다[58].

우라늄이 산에 용해된 수용성 공정에서와 달리 비수용 성 공정에서는 우라늄을 어떠한 형태로 이온성 액체에 용해 시킬 수 있는지가 선결되어야 용액 중에서 전기화학 거동 측 정이 의미를 갖게 된다. 최근에는 수용성 공정에서와 같이 $\mathrm{TBP}-\mathrm{HNO}_{3}$ 복합체를 포함하고 있는 imidazolium 계열의 이 온성 액체에 $\mathrm{UO}_{2}$ 가 직접 용해되며 $\mathrm{TBP}$ 와 $1: 2$ 의 배위 결합을 하고 있음이 보고되었다[59]. 더 나아가 이렇게 용해된 $\mathrm{UO}_{2}$ 를 전기화학적 방법이 아닌 초임계 이산화탄소를 이용하여 추출하였으며 최종적으로는 물/n-DD 트랩으로 복합체 형태 의 우라늄을 회수하였다[59]. 이와 같이 우라늄이 어떻게 이 온성 액체에 용해되는지는 상당히 중요한 연구 주제로 앞 서 언급된 연구 그룹은 이를 알아보기 위해 우라늄을 질화 물 복합체 형태로 용해시켜 imidazolium 계열의 이온성 액 체에서 FTIR 방법으로 분석하였으며 질산 이온과의 결합으 로 $\mathrm{UO}_{2}\left(\mathrm{NO}_{3}\right)_{\mathrm{n}}(\mathrm{n}=0,1,2,3)$ 형태의 복합체가 형성되는 것 
을 보고하였다[60]. 이러한 복합체 형성에 대한 질산염, 과염 소산염, 물의 영향이 Raman, ATR-FTIR 및 NMR의 분광학적 인 방법으로 연구되어 우라늄 복합물의 배위 환경에 대한 방 법이 제시되었다[61].

Giridhar 등은[62] [bmim][Cl]에 우라늄을 용해시키기 위 해 알카리 금속과 염화물 형태로 $\left(\mathrm{Na}_{2} \mathrm{UO}_{2} \mathrm{Cl}_{4}\right.$ 및 $\left.\mathrm{Cs}_{2} \mathrm{UO}_{2} \mathrm{Cl}_{4}\right)$ $\mathrm{U}(\mathrm{VI})$ 를 제조하여 환원전위를 측정하였으며 일정 전류를 인 가하여 우라늄 산화물을 석출시켜 얻었으며 EDXRF와 XRD 분석법으로 확인하였다. 이러한 연구와는 별도로 전형적인 이온성 액체에서 다소 빗겨난 형태인 이온성 액체에 단순 alkyl기를 붙이지 않고 carboxyl기를 붙여 우라늄 산화물을 용해시켜 우라늄 복합체를 형성시킨 연구 역시 우라늄의 이 온성 액체 용해를 위한 연구의 일환으로 볼 수 있다[63].

우라늄을 제외한 악티나이드 금속의 전기화학 거동 연구 는 많이 진행되지는 않았다. 1980년대 이온성 액체에서 우 라늄의 전기화학적 거동 연구가 본격적으로 시작되었을 때 $\mathrm{Np}$ 의 전기화학적, 분광학적 연구가 함께 진행되었다[64]. 이 시스템은 1980년대 우라늄 연구와 마찬가지로 $\mathrm{AlCl}_{3}$ 가 포함 된 시스템이었으며 이 후 Nikitenko와 Moisy는 소수성 이온 성 액체이며 보다 범용적으로 사용되는 [bmim] 시스템에서 $\mathrm{Np}(\mathrm{IV})$ 과 $\mathrm{Pu}(\mathrm{IV})$ 염화물들의 복합물 형성을 분광학적으로 측정하였다[65]. Th의 경우 다소 복잡한 화합물 형태로 합성 되어 열중량 분석, 분광학 분석 등과 연계되어 실온 이온성 액체에서 환원 전위가 측정되었다. 실험 결과 $\mathrm{Th}(\mathrm{IV})$ 은 단일 단계를 통하여 $\mathrm{Th}(0)$ 으로 환원되었으나 최종적으로는 물과 의 반응에 의해 $\mathrm{ThO}_{2}$ 로 석출되었다[66]. 또한, 환원 전위 측 정 결과 $\mathrm{LiCl}-\mathrm{KCl}$ 공융염, 물, 비수용성 용매계에서 보다 이 온성 액체 계에서 보다 쉽게 환원되는 것으로 나타났다[66].

분열생성물들에 대한 전기화학적 거동에 대한 연구는 일 부를 제외하고는 사용후핵연료 처리를 염두해 두고 진행되 지는 않았으며 이온성 액체를 이용한 금속 회수 측면에서 진 행 되었다. Cs의 경우 수은을 전극으로 사용하여 $97 \%$ 효율로 tri-1-butylmethylammonium 계에서 회수될 수 있다는 것이 보고되었다[67]. Eu을 포함하는 란타나이드 금속들에 대한 연구는 앞서 언급된 U과 악티나이드들과 동일하게 1980년 대 $\mathrm{AlCl}_{3}$ 를 포함하는 산성 이온성 액체 시스템에서 수행되었 다[68,69]. 앞서 언급된 Th의 전해환원을 연구한 연구자들은 Th 연구 이전에 동일한 이온성 액체를 $\mathrm{La}, \mathrm{Sm}, \mathrm{Eu}$ 에 적용하 여 전기화학적 거동을 측정하였다[70]. 이온성 액체 내의 복 합체에서 금속 원소들을 환원시켜 금속을 얻었으나 범용적으 로 사용되는 이온성 액체를 사용하지 않아 U 거동이 중심이
되는 사용후핵연료를 대상으로 직접 적용하기에는 무리가 있으나 전기화학적으로 란타나이드를 회수할 수 있음을 실 험적으로 보여준 것에 의미가 있다. 이 후의 연구들에서는 보 다 넓은 범위에서 사용되는 imidazolium 계와 pyrrolidinium 계열의 이온성 액체에서 란타나이드 중 일부 금속 원소들의 전기 화학적 거동을 측정하여 확산계수들과 산화-환원 전위 등의 물성들을 보고하였다[71,72]. 귀금속 계열의 원소들에 대한 이온성 액체에서의 전기화학 거동은 Jayakumar 등[7375]에 의해 중점적으로 연구되었다. 이 들은 가장 많이 사용 되는 이온성 액체인 $[\mathrm{bmim}][\mathrm{Cl}]$ 계에서 $\mathrm{Pd}, \mathrm{Rd}, \mathrm{Ru}$ 의 전기화 학 거동들을 차례로 보고하였으며 확산계수들과 환원 전위 를 측정하였다.

\section{4. 이온성 액체의 방사화학 안정성}

사용후핵연료에 존재하는 원소들은 방사능을 나타내는 방사성 동위원소들이다. 화학적 성질에서 비방사성 원소들 과 동일하여 추출 및 환원전위 등에서 동일한 특성들을 보일 것이 예상되나 발생되는 방사능에 의한 매질의 안정성은 방 사성 원소들을 이용하여 측정되어야 사용후핵연료 처리 과 정에서 이온성 액체의 활용성을 판단할 수 있게 된다. 파이 로 공정에서 사용되는 $\mathrm{LiCl}$ 이나 $\mathrm{KCl}$ 과 같은 단순 무기염들은 분자구조가 간단하여 방사능에 대한 비교적 안정적인 용매 역할을 한다. 반면, 이온성 액체는 복잡한 구조와 긴 체인을 양이온이 포함하므로 방사능에 대한 이들의 안정성이 중요 한 연구 주제가 된다.

Allen 등은[76] 질산염과 염소 음이온과 결합된 1,3-alkylmethylimidazolium 양이온에 대한 안정성을 $400 \mathrm{kGy}$ 까 지의 방사선량에서 측정하여 보고하였다. 대상 이온성 액체 용액은 PUREX 공정에서 사용되는 $\mathrm{TBP} /$ 등유 용액에 대해 더 높은 수준의 안정성을 보이는 것으로 나타나 $400 \mathrm{kGy}$ 에 서 $\mathrm{TBP} /$ 등유 용액의 $15 \%$ 가 분해된 반면 이온성 액체는 단지 $1 \%$ 만이 분해되는 것으로 측정되었다. 보다 높은 방사능 범 위에서 (1200 kGy) Berthon 등은[77] [bmim][ $\left.\mathrm{PF}_{6}\right]$ 와 [bmim] $\left[\mathrm{NTf}_{2}\right]$ 를 대상으로 ${ }^{137} \mathrm{Cs}$ 을 이용하여 감마선 방사화학 안정성 을 측정하였으며 밀도, 표면 장력 등의 물성이 변하지 않는 것을 관찰하였다. 그러나 [bmim]의 분해에 의한 라디칼 생성 으로 용액이 어두워졌으며 빛의 흡수율이 증가되는 것을 발 견하였다. 이온성 액체 음이온-양이온 구성에 의한 안정성 영향을 판단하기 위해 imidazolium 계열의 이온성 액체에 
서 다양한 음이온을 사용하여 상당히 높은 (2.0 MGy) 수준 의 방사화학 영향이 방사분해 생성물들과 함께 보고되었으 며[78] imidazolium 계열이 아닌 이온성 액체에서도 감마선 의 영향이 측정되었다[79,80]. Methyltributylammonium 양 이온을 지닌 이온성 액체는 $2 \mathrm{MGy}$ 수준의 조사에서도 안정 한 것이 확인되었다[79]. 반면 azolium 계열의 이온성 액체 에서는 $1.2 \mathrm{MGy}$ 의 감마선 조사에 의해 전기 전도도가 감소 되었으며 전기화학 창이 적어도 $1.1 \mathrm{~V}$ 축소되는 것으로 관 찰되었다[80].

방사성 분해에 의한 단순한 이온성 액체의 물성 변화 측 정을 넘어 실제 추출 공정에서 방사화학적 영향이 어떻게 작 용하는지에 대한 연구들은 비교적 최근에 진행되었다. $\mathrm{Sr}^{2+}$ 추출을 위해 crown ether를 포함한 [bmim][PF, $]$ 이온성 액 체에 감마선을 조사한 결과 생성된 $\mathrm{H}^{+}$이온이 $\mathrm{Sr}^{2+}$ 와 경쟁 하여 추출상의 $\mathrm{Sr}^{2+}$ 분배를 저하시키는 영향을 보이는 것으 로 나타났다[81]. [bmim][NTf $\left.f_{2}\right]$ 에서는 감마선 조사에 의해 $\mathrm{CF}_{3} \mathrm{SO}_{2} \mathrm{OH}, \mathrm{CF}_{3} \mathrm{SOOH}, \mathrm{CF}_{3} \mathrm{SO}_{2} \mathrm{NH}_{2}, \mathrm{HF}, \mathrm{H}_{2} \mathrm{SO}_{4}$ 및 $\mathrm{H}^{+}$와 같이 다양한 방사 분해 생성물들이 발견되었으며 물에 용해되는 물질들은 $\mathrm{Sr}^{2+}$ 추출에 크게 영향을 미쳐 추출 성능을 저하시 키는 것으로 보고되었다[82].

\section{5. 결론}

본 연구에서는 최근 다양한 화학 공정에서 친환경 용매 로 주목 받고 있는 이온성 액체가 어떻게 방사성 폐기물 처 리 공정에 적용될 수 있는지 판단하기 위하여 현재까지의 주 요 연구 결과들을 정리하여 제시하였다. 이온성 액체는 그 자체가 금속 이온을 추출할 수 있는 추출제로 사용되는 것 은 아니며 추출제를 희석하여 수용액 상과 상분리를 발생시 키기 위한 소수성 용매로 사용된다. 한편, 이온성 액체로 추 출된 금속 원소들은 전기화학적으로 회수될 수 있기 때문에 이온성 액체에서 활용되는 주목할 만한 특성으로는 추출제 를 용해시키는 소수성 성질과 전해반응 매질로서 넓은 전기 화학 창을 들 수 있다.

사용후핵연료 처리 공정을 수용성 공정과 비수용성 공정 으로 구분한다면 추출-전해회수 방법은 수용성 공정으로 이 해할 수 있으며 용해-전해회수 방법은 비수용성 공정으로 분 류할 수 있다. 본 논문에서는 이와 같은 분류를 기준으로 우 라늄, 악티나이드, 란타나이드 및 주요 분열생성물을 대상으 로 연구된 결과들을 정리하였으며 사용후핵연료 처리에 필
수적으로 고려되어야하는 방사화학 안정성에 대한 연구들 또한 정리하였다.

이온성 액체는 다양한 양이온과 음이온 조합으로 원하는 물성을 갖춘 용매를 만들 수 있다는 측면에서 매력적인 물질 이긴 하지만 다소 복잡한 구조에 의해 추출 또는 용해되어 있 는 금속 원소들의 배위 환경에 대한 이해가 선행되어야한다. 따라서, 현재까지의 연구는 화학적 접근으로 분광학적 분석 과 전기화학적 물성 측정에 집중되어 있는 것으로 볼 수 있 다. 사용후핵연료 및 방사성 폐기물 처리 공정에 적용을 위 한 실제적인 접근으로 우라늄 및 여타 금속 원소들을 포함하 고 있는 다성분 계에서 추출 성능과 전기화학 거동이 이온성 액체를 이용한 공정 개발을 위해서 필요한 것으로 판단된다. 이에 더불어 핵확산 저항성 측면에서 $\mathrm{Pu}$ 이 어떻게 독자적으 로 분리되지 않을지에 대한 과학적, 기술적 연구 또한 병행 되어야 할 것으로 보인다. 이온성 액체가 다양한 양이온-음 이온 조합이 가능하므로 이에 대한 연구 범위는 상당히 넓게 되며 만약 성공적으로 이러한 목적에 맞는 이온성 액체와 공 정이 개발된다면 PUREX 공정에 비해 친환경적이며 폐기물 이 저감된 공정으로, 파이로 공정에 비해 보다 온화한 조건 에서 운전되어 반응기 재질 등에서 안정성이 향상된 공정으 로 개발될 수 있을 것으로 기대된다.

\section{REFERENCES}

[1] DOE/EIA Report, "Annual Energy Review 2011", DOE/EIA-0384 (2012).

[2] IAEA Report, "Status and Trends in Spent Fuel Reprocessing”, IAEA-TECDOC-1497 (2005).

[3] IAEA Report, "Spent Fuel Reprocessing Options", IAEA-TECDOC-1587 (2008).

[4] G.R. Choppin, M.K. Khankhasayev, and H.S. Plendl, Eds., Chemical Separations in Nuclear Waste Management: The State of the Art and a Look to the Future, Battelle Press (2002).

[5] J.J. Laidler, J.E. Battles, W.E. Miller, J.P. Ackerman, and E.L. Carls, "Development of Pyroprocessing Technology", Prog. Nucl. Energ., 31, pp. 131-140 (1997).

[6] C.C. McPheeters, R.D. Pierce, and T.P. Mulcahey, "Application of the Pyrochemical Process to Recycle 
of Actinides from LWR Spent Fuel", Prog. Nucl. Energ., 31, pp. 175-186 (1997).

[7] T. Usami, M. Kurata, T. Inoue, H. E. Sims, S. A. Beetham, and J. A. Jenkins, "Pyrochemical Reduction of Uranium Dioxide and Plutonium Dioxide by Lithium Metal", J. Nucl. Mater., 300, pp. 15-26 (2002).

[8] K.C. Song, H. Lee, J.M. Hur, J.G. Kim, D.H. Ahn, and Y.Z. Cho, "Status of Pyroprocessing Technology Development in Korea”, Nucl. Eng. Technol., 42, pp. 131-144 (2010).

[9] H. Lee, G.I. Park, K.H. Kang, J.M. Hur, J.G. Kim, D.H. Ahn, Y.Z. Cho, and E. H. Kim, "Pyroprocessing Technology Developement at KAERI", Nucl. Eng. Technol., 43, pp. 317-328 (2011).

[10] K.A. Venkatesan, T.G. Srinivasan, and P.R. Vasudeva Rao, "A Review on the Electrochemical Applications of Room Temperature Ionic Liquids in Nuclear Fuel Cycle", J. Nucl. Radiochem. Sci., 10, R1-R6 (2009).

[11] S.H. Ha, R.N. Menchavez, and Y.M. Koo, "Reprocessing of Spent Nuclear Waste Using Ionic Liquids", Korean J. Chem. Eng., 27, pp. 1360-1365 (2010).

[12] P.R. Vasudeva Rao, K.A. Venkatesan, A. Rout, T.G. Srinivasan, and K. Nagarajan, "Potential Applications of Room Temperature Ionic Liquids for Fission Products and Actinide Separation". Sep. Sci. Technol., 47, pp. 204-222 (2012).

[13] B. Kirchner, Eds., Ionid Liquids, Springer (2010).

[14] M. Gaune-Escard and K.R. Seddon, Eds, Molten Salts and Ionic Liquids: Never the Twain?, Wiley (2010).

[15] R.D. Rogers and K.R. Seddon, "Ionic Liquids - Solvents of the Future?”, Science, 302, pp. 792-793 (2003).

[16] J.G. Huddleston and R.D. Rogers, "Room Temperature Ionic Liquids as Novel Media for 'Clean' Liquid-Liquid Extraction", Chem. Commun., Issue 16, pp. 1765-1766 (1998).

[17] A.E. Visser, R.P. Swatloski, S.T. Griffin, D.H. Hart- man, and R.D. Rogers, "Lquid/liquid Extraction of Metal Ions in Room Temperature Ionic Liquids", Sep. Sci. Technol., 36, pp. 785-804 (2001).

[18] A.E. Visser, R.P. Swatloski, W.M. Reichert, R. Mayton, S. Sheff, A. Wierzbicki, J.H. Davis Jr., and R.D. Rogers, "Task-specific Ionic Liquids for the Extraction of Metal Ions from Aqueous Solutions", Chem. Commun., Issue 1, pp. 135-136 (2001).

[19] M.L. Dietz, "Ionic Liquids as Extraction Solvents: Where do We Stand?", Sep. Sci. Technol., 41, pp. 2047-2063 (2006).

[20] M. Galiński, A. Lewandowski, and I. Stępniak, "Ionic Liquids as Electrolytes", Electrochim. Acta, 51, pp. 5567-5580 (2006).

[21] M. Hayyan, F.S. Mjalli, M.A. Hashim, I.M. AlNashef, and T.X. Mei, "Investigation the Electrochemical Windows of Ionic Liquids", J. Ind. Eng. Chem., 19, pp. 106-112 (2013).

[22] S.S. Moganty, R.E. Baltus, and D. Roy, "Electrochemical Windows and Impedance Characteristics of $\left[\mathrm{Bmim}^{+}\right]\left[\mathrm{BF}_{4}\right]$ and $\left[\mathrm{Bdmim}^{+}\right]\left[\mathrm{BF}_{4}\right]$ Ionic Liquids at the Surfaces of $\mathrm{Au}, \mathrm{Pt}, \mathrm{Ta}$ and Glassy Carbon Electrodes", Chem. Phys. Lett., 483, pp. 90-94 (2009).

[23] F. Endres, "Ionic Liquids: Solvents for the Electrodeposition of Metals and Semiconductors", Chemphyschem, 3, pp. 144-154 (2002).

[24] W. Simka, D. Puszczyk, and G. Nawrat, "Electrodeposition of Metals from Non-aqueous Solutions", Electrochim. Acta, 54, pp. 5307-5319 (2009).

[25] A.P. Abbott and K.J. McKenzie, "Application of Ionic Liquids to the Electrodeposition of Metals", Phys. Chem. Chem. Phys., 8, pp. 4265-4279 (2006).

[26] A.E. Visser and R.D. Rogers, "Room-temperature Ionic Liquids: New Solvents for F-element Separations and Associated Solution Chemistry", J. Solid State Chem, 171, pp. 109-113 (2003).

[27] Z. Kolarik, "Ionic Liquids: How Far Do they Extend the Potential of Solvent Extraction of f-Elements?", 
Solvent Extr. Ion Exch., 31, pp. 24-60 (2013).

[28] P. Giridhar, K.A. Venkatesan, T.G. Srinivasa, and P.R. Vasudeva Rao, "Extraction of Uranium(VI) from Nitric Acid Medium by 1.1 M Tri-n-butylphosphate in Ionic Liquid Diluent", J. Radioanal. Nucl. Chem., 265, pp. 31-38 (2005).

[29] P. Giridhar, K.A. Venkatesan, T.G. Srinivasan, and P.R. Vasudeva Rao, "Effect of Alkyl Group in 1-Alkyl-3-methylimidazolium Hexafluorophosphate Ionic Liquids on the Extraction of Uranium by Trin-butylphosphate Diluted with Ionic Liquids", J. Nucl. Radiochem. Sci, 5, pp. 21-26 (2004).

[30] P. Giridhar, K.A. Venkatesan, S. Subramaniam, T.G. Srinivasan, and P.R. Vasudeva Rao, "Extraction of Uranium(VI) by 1.1 M Tri-n-butylphosphate/ Ionic Liquid and the Feasibility of Recovery by Direct Electrodeposition from Organic Phase", J. Alloys Compd, 448, pp. 104-108 (2008).

[31] P. Giridhar, K.A. Venkatesan, T.G. Srinivasan, and P.R. Vasudeva Rao, "Electrochemical Behavior of Uranium(VI) in 1-butyl-3-methylimidazolium Chloride and Thermal Characterization of Uranium Oxide Deposit", Electrochim. Acta, 52, pp. 30063012 (2007).

[32] P. Giridhar, K.A. Venkatesan, T.G. Srinivasan, and P.R. Vasudeva Rao, "Comparison of Diluent Characteristics of Imidazolium Hexafluophosphate Ionic Liquid with n-Dodecane", J. Nucl. Radiochem. Sci, 5, pp. 17-20 (2004).

[33] A.E. Visser, M.P. Jensen, I. Laszak, K.L. Nash, G.R. Choppin, and R.D. Rogers, "Uranyl Coordination Environment in Hydrophobic Ionic Liquids: An in Situ Investigation", Inorg. Chem., 42, pp. 2197-2199 (2003).

[34] C. Gaillard, O. Klimchuk, A. Ouadi, I. Billard, and $\mathrm{C}$. Hennig, "Evidence for the formation of $\mathrm{UO}_{2}\left(\mathrm{NO}_{3}\right)_{4}{ }^{2-}$ in an ionic liquid by EXAFS", Dalton Trans., 41, pp. 5476-5479 (2012).

[35] M.L. Dietz and D.C. Stepinski, "Anion Concentration-dependent Partitioning Mechanism in the Extraction of Uranium into Room-temperature Ionic
Liquids", Talanta, 75, pp. 598-603 (2008).

[36] A. Ouadi, O. Klimchuk, C. Gaillard, and I. Billard, "Solvent Extraction of U(VI) by Task Specific Ionic Liquids Bearing Phosphoryl Groups”, Green Chem., 9, pp. 1160-1162 (2007).

[37] T.J. Bell and Y. Ikeda, "The Application of Novel Hydrophobic Ionic Liquids to the Extraction of Uranium(VI) from Nitric Acid Medium and a Determination of the Uranyl Complexes Formed", Dalton Trans., 40, pp. 10125-10130 (2011).

[38] M. Srncik, D. Kogelnig, A. Stojanovic, W. Körner, R. Krachler, and G. Wallner, "Uranium Extraction from Aqueous Solutions by Ionic Liquids", Appl. Radiat. Isot., 67, pp. 2146-2149 (2009).

[39] Z. Kolarik, U. Müllich, and F. Gassner, "Selective Extraction of Am(III) over Eu(III) BY 2,6-ditriazolyl- and 2,6-ditriazinylpyridines", Solvent Extr. Ion Exch., 17, pp. 23-32 (1999).

[40] Y. Zuo, Y. Liu, J. Chen, and D.Q. Li, "The Separation of Cerium(IV) from Nitric Acid Solutions Containing Thorium(IV) and Lanthanides(III) Using Pure $\left[\mathrm{C}_{8} \mathrm{mim}\right] \mathrm{PF}_{6}$ as Extracting Phase", Ind. Eng. Chem. Res., 47, pp. 2349-2355 (2008).

[41] K. Shimojo, K. Kurahashi, and H. Naganawa, "Extraction Behavior of Lanthanides using a Diglycolamide Derivative TODGA in Ionic Liquids", Dalton Trans., 37, pp. 5083-5088 (2008).

[42] F. Kubota, Y. Koyanagi, K. Nakashima, K. Shimojo, N. Kamiya, and M. Goto, "Extraction of Lanthanide Ions an Organophosphorous Extractant into Ionic Liquids", Solvent Extr. Res. Dev. Jpn., 15, pp. 81-87 (2008).

[43] A. Sengupta, P.K. Mohapatra, M. Igbal, W. Verboom, J. Huskens, and S.V. Godbole, "Extraction of Am(III) Using Novel Solvent Systems Containing a Tripodal Diglycolamide Ligand in Room Temperature Ionic Liquids: a 'Green' Approach for Radioactive Waste Pprocessing”, RSC Adv., 2, pp. 7492-7500 (2012).

[44] S. Dai, Y.H. Ju, and C.E. Barnes, "Solvent Extraction of Strontium Nitrate by a Crown Ether using 
Room-temperature Ionic Liquids", J. Chem. Soc. Dalton Trans., Issue 8, pp. 1201-1202 (1999).

[45] A.E. Visser, R.P. Swatloski, W.M. Reichert, S.T. Griffin, and R.D. Rogers, "Traditional Extractants in Nontraditional Solvents: Groups 1 and 2 Extraction by Crown Ethers in Room-Temperature Ionic Liquids", Ind. Eng. Chem. Res., 39, pp. 35963604 (2000).

[46] M.L. Dietz and J.A. Dzielawa, "Ion-exchange as a Mode of Cation Transfer into Room-temperature Ionic Liquids Containing Crown Ethers: Implications for the 'Greenness' of Ionic Liquids as Diluents in Liquid-Liquid Extraction", Chem. Commun. Issue 20, pp. 2124-2125 (2001).

[47] S. Chun, S.V. Dzyuba, and R.A. Bartsch, "Influ ence of Structural Variation in Room-temperature Ionic Liquids on the Selectivity and Efficiency of Competitive Alkali Metal Salt Extraction by a Crown Ether", Anal. Chem., 73, pp. 3737-3741 (2001).

[48] H. Luo, J.F. Huang, and S. Dai, "Solvent Extraction of $\mathrm{Sr}^{2+}$ and $\mathrm{Cs}^{+}$using Protic Amide-Based Ionic Liquids", Sep. Sci. Technol., 45, pp. 16791688 (2010).

[49] P.Y. Chen and C.L. Hussey, "Electrochemistry of Ionophore-coordinated $\mathrm{Cs}$ and $\mathrm{Sr}$ Ions in the Tri1-butylmethylammonium Bis((trifluoromethyl)sulfonyl)imide Ionic Liquid", Electrochim. Acta, 50, pp. 2533-2540 (2005).

[50] P.Y. Chen, "The Assessment of Removing Strontium and Cesium Cations from Aqueous Solutions Based on the Combined Methods of Ionic Liquid Extraction and Electrodeposition", Electrochim. Acta, 52, pp. 5484-5492 (2007).

[51] V.A. Cocaila, K.E. Gutowski, and R.D. Rogers, "The Coordination Chemistry of Actinides in Ionic Liquids: A Review of Experiment and Simulation", Coord. Chem., Rev., 250 pp. 755-764 (2006).

[52] K. Takao, T.J. Bell, and Y. Ikeda, "Actinide Chemistry in Ionic Liquids", Inorg. Chem., 52, pp. 34593472 (2013).
[53] R. De Waele, L. Heerman, and W. D'Olieslager, "Electrochemistry of Uranium(IV) in Acidic $\mathrm{AlCl}_{3}+\mathrm{N}$-(n-butyl)pyridinium Chloride Room-temperature Molten Salts", J. Electroanal. Chem., 142, pp.137-146 (1982).

[54] L. Heerman, R. De Waele, and W. D'Olieslager, "Electrochemistry and Spectroscopy of Uranium in Basic $\mathrm{AlCl}_{3}+\mathrm{N}$-(n-butyl)pyridinium Chloride Room Temperature Molten Salts", J. Electroanal. Chem., 193, pp.289-294 (1985).

[55] C.J. Anderson, M.R. Deakin, G.R. Choppin, W. D'Olieslager, L. Heerman, and D.J. Pruett, "Spectroscopy and Electrochemistry of Uranium(IV)/ uranium(III) in Basic Aluminum Chloride-1-ethyl3-methylimidazolium Chloride", Inorg. Chem., 30, pp. 4013-4016 (1991).

[56] R. De Waele, L. Heerman, and W. D'Olieslager, "Potentiometric and Spectroscopic Study of Uranium(IV)-uranium(III) in Acidic $\mathrm{AlCl}_{3}-\mathrm{N}$-(n-butyl) pyridinium Chloride Melts", J. Less Common Metals, 122, pp. 319-327 (1986).

[57] P.B. Hitchcock, T.J. Mohammed, K.R. Seddon, J.A. Zora, C.L. Hussey, and E.H. Ward, "1-methyl-3-ethylimidazolium Hexachlorouranate(IV) and 1-methyl-3-ethylimidazolium Tetrachlorodioxouranate(VI): Synthesis, Structure, and Electrochemistry in a Room Temperature Ionic Liquid", Inorg. Chim. Acta, 113, L25-L26 (1986).

[58] S.I. Nikitenko, C. Cannes, C. Le Naour, P. Moisy, and D. Trubert, "Spectroscopic and Electrochemical Studies of U(IV)-Hexachloro Complexes in Hydrophobic Room-temperature Ionic Liquids [BuMeIm] $\left[\mathrm{Tf}_{2} \mathrm{~N}\right]$ and $\left[\mathrm{MeBu}_{3} \mathrm{~N}\right]\left[\mathrm{Tf}_{2} \mathrm{~N}\right]$ ", Inorg. Chem., 44, pp. 9497-9505 (2005).

[59] C.M. Wai, Y.J. Liao, W. Liao, G. Tian, R.S. Addleman, D. Quach, and S.P. Pasilis, "Uranium Dioxide in Ionic Liquid with a Tri-n-butylphosphate- $\mathrm{HNO}_{3}$ Complex-Dissolution and Coordination Environment", Dalton Trans., 40, pp. 5039-5045 (2011).

[60] D.L. Quach, C.M. Wai, and S.P. Pasilis, "Characterization of Uranyl(VI) Nitrate Complexes in 
a Room Temperature Ionic Liquid Using Attenuated Total Reflection-Fourier Transform Infrared Spectrometry", Inorg. Chem., 49, pp. 8568-8572 (2010).

[61] S.P. Pasilis and A. Blumenfeld, "Effect of Nitrate, Perchlorate, and Water on Uranyl(VI) Speciation in a Room-Temperature Ionic Liquid: A Spectroscopic Investigation”, Inorg. Chem., 50, pp. 83028307 (2011).

[62] P. Giridhar, K.A. Venkatesan, S. Subramaniam, T.G. Srinivasan, and P.R. Vasudeva Rao, "Electrochemical Behavior of Uranium(VI) in 1-butyl3-methylimidazolium Chloride and in 0.05 M Aliquat-336/chloroform", Radiochim. Acta, 94, pp. 415-420 (2006).

[63] P. Nockemann, R. Van Deun, B. Thijs, D. Huys, E. Vanecht, K. Van Hecke, L. Van Meervelt, and K. Binnemans, "Uranyl Complexes of CarboxylFunctionalized Ionic Liquids", Inorg. Chem., 49, pp. 3351-3360 (2010).

[64] J.P. Schoebrechts and B. Gilbert, "Electrochemical and Spectroscopic Studies of Neptunium in the Aluminum Chloride-1-n-butylpyridinium Chloride Melt at $40^{\circ} \mathrm{C} "$, Inorg. Chem., 24, pp. 2105-2110 (1985).

[65] S.I. Nikitenko and P. Moisy, "Formation of Higher Chloride Complexes of $\mathrm{Np}(\mathrm{IV})$ and $\mathrm{Pu}(\mathrm{IV})$ in WaterStable Room-Temperature Ionic Liquid [BuMeIm] [Tf $\left.{ }_{2} \mathrm{~N}\right]$ ", Inorg. Chem., 45, pp. 1235-1242 (2006).

[66] A.I. Bhatt, N.W. Duffy, D. Collison, I. May, and R.G. Lewin, "Cyclic Voltammetry of Th(IV) in the Roomtemperature Ionic Liquid $\left[\mathrm{Me}_{3} \mathrm{NnBu}\right]\left[\mathrm{N}\left(\mathrm{SO}_{2} \mathrm{CF}_{3}\right)_{2}\right]$ ", Inorg. Chem., 45, pp. 1677-1682 (2006).

[67] P.Y. Chen and C.L. Hussey, "Electrodeposition of Cesium at Mercury Electrodes in the Tri-1-butylmethylammonium Bis((trifluoromethyl)sulfonyl)imide Room-temperature Ionic Liquid", Electrochim. Acta, 49, pp. 5125-5138 (2004).

[68] J.P. Schoebrechts, B.P. Gilbert, and G. Duyckaerts, "Electrochemical and Spectroscopic Studies of the Lanthanides in the $\mathrm{AlCl}_{3}+1$-n-butylpyridinium
Chloride Melt at $40^{\circ} \mathrm{C}$ : Part I. The Yb(III-II), Sm(IIIII) Systems", J. Electroanal. Chem. Interfacial Electrochem., 145, pp. 127-138 (1983).

[69] J.P. Schoebrechts, B.P. Gilbert, and G. Duyckaerts, "Electrochemical and Spectroscopic Studies of the Lanthanides in the $\mathrm{AlCl}_{3}+1$-n-butylpyridinium Chloride Melt at $40^{\circ} \mathrm{C}$ : Part II. The Tm(III-II), Eu(IIIII) Systems, Application of Nugent's Linearization Method", J. Electroanal. Chem. Interfacial Electrochem., 145, pp. 139-146 (1983).

[70] A.I. Bhatt, I. May, V.A. Volkovich, D. Collison, M. Helliwell, I.B. Polovov, and R.G. Lewin, "Structural Characterization of a Lanthanum Bistriflimide Complex, $\mathrm{La}\left(\mathrm{N}\left(\mathrm{SO}_{2} \mathrm{CF}_{3}\right)_{2}\right)_{3}\left(\mathrm{H}_{2} \mathrm{O}\right)_{3}$, and an Investigation of $\mathrm{La}, \mathrm{Sm}$, and $\mathrm{Eu}$ Electrochemistry in a Room-temperature Ionic Liquid, $\left[\mathrm{Me}_{3} \mathrm{NnBu}\right]$ $\left[\mathrm{N}\left(\mathrm{SO}_{2} \mathrm{CF}_{3}\right)_{2}\right]$ ", Inorg. Chem., 44, pp. 4934-4940 (2005).

[71] M. Yamagata, Y. Katayama, and T. Miura, "Electrochemical Behavior of Samarium, Europium, and Ytterbium in Hydrophobic Room-temperature Molten Salt Systems", J. Electrochem. Soc., 153, E5E9 (2006).

[72] C.J. Rao, K.A. Venkatesan, K. Nagarajan, T.G. Srinivasan, and P.R. Vasudeva Rao, "Electrochemical Behavior of Europium(III) in N-butyl-N-methylpyrrolidinium Bis(trifluoromethylsulfonyl)imide", Electrochim. Acta, 54, pp. 4718-4725 (2009).

[73] M. Jayakumar, K.A. Venkatesan, and T.G. Srinivasan, "Electrochemical Behavior of Fission Palladium in 1-butyl-3-methylimidazolium Chloride", Electrochim. Acta, 52, pp. $7121-7127$ (2007).

[74] M. Jayakumar, K.A. Venkatesan, and T.G. Srinivasan, "Electrochemical Behavior of Rhodium(III) in 1-butyl-3-methylimidazolium Chloride Ionic Liquid", Electrochim. Acta, 53, pp. 2794-2801 (2008).

[75] M. Jayakumar, K.A. Venkatesan, T.G. Srinivasan, and P.R. Vasudeva Rao "Electrochemical Behavior of Ruthenium(III), Rhodium(III) and Palladium(II) in 1-butyl-3-methylimidazolium Chloride Ionic Liquid", Electrochim. Acta, 54, pp. 6747-6755 (2009). 
[76] D. Allen, G. Baston, A.E. Bradley, T. Gorman, A. Haile, I. Hamblett, J.E. Hatter, M.J.F. Healey, B. Hodgson, R. Lewin, K.V. Lovell, B. Newton, W.R. Pitner, D.W. Rooney, D. Sanders, K.R. Seddon, H.E. Sims, and R.C. Thield, "An Investigation of the Radiochemical Stability of Ionic Liquids", Green Chem., 4, pp. 152-158 (2002).

[77] L. Berthon, S.I. Nikitenko, I. Bisel, C. Berthon, M. Faucon, B. Saucerotte, N. Zorz, and Ph. Moisy, "Influence of Gamma Irradiation on Hydrophobic Room-temperature Ionic Liquids [BuMeIm] $\mathrm{PF}_{6}$ and [BuMeIm] $\left(\mathrm{CF}_{3} \mathrm{SO}_{2}\right)_{2} \mathrm{~N}$ ", Dalton Trans., pp. 25262534 (2006).

[78] G. Le Rouzo, C. Lamouroux, V. Dauvois, A. Dannoux, S. Legand, D. Durand, P. Moisly, and G. Moutiers, "Anion Effect on Radiochemical Stability of Room-temperature Ionic Liquids under Gamma Irradiation", Dalton Trans., pp. 6175-6184 (2009).

[79] É. Bossé, L. Berthon, N. Zorz, J. Monget, C. Berthon, I. Bisel, S. Legand, and P. Moisy, "Stability of [MeBu3N][Tf2N] under Gamma Irradiation”, Dalton Trans., pp. 924-931 (2008).

[80] N.J. Bridges, A.E. Visser, M.J. Williamson, J.I. Mickalonis, and T.M. Adams, "Effects of Gamma Radiation on Electrochemical Properties of Ionic Liquids", Radiochim. Acta, 98, pp. 243-247 (2010).

[81] L. Yuan, J. Peng, L. Xu, M. Zhai, J. Li, and G. Wei, "Influence of g-radiation on the Ionic Liquid [ $\left.\mathrm{C}_{4} \mathrm{mim}\right]$ $\left[\mathrm{PF}_{6}\right]$ during Extraction of Strontium Ions", Dalton Trans., pp. 6358-6360 (2008).

[82] Y. Ao, J. Peng, L. Yuan, Z. Cui, C. Li, J. Li, and M. Zhai, "Identification of Radiolytic Products of $\left[\mathrm{C}_{4} \mathrm{mim}\right]\left[\mathrm{NTf}_{2}\right]$ and Their Effects on the $\mathrm{Sr}^{2+}$ Extraction”, Dalton Trans., 42, pp. 4299-4305 (2013). 